Oxford, 1969, Chapter 4-2.

(25) An alternate explanation, involving retro-Mannich scission of the cyclohexane ring (eq i), appears ruled out since such a process can lead to ep-

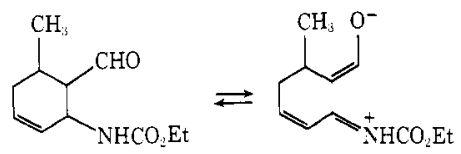

imerization at both the methyl- and aldehyde-bearing ring carbons. The all-trans adduct 14 would be expected to result from such an epimerization mechanism.

(26) Unpublished observations of G. F. Taylor and P. J. Jessup.

(27) Prepared from ethyl butyrate by the method of Corey and Kwiatkowski: $E$. J. Corey and G. T. Kwiatkowski, J. Am. Chem. Soc, 88, 5653 (1966).

(28) P. N. Rylander, "Catalytic Hydrogenation over Platinum Metals", Academic Press, New York, N.Y., 1967, Chapter 25.

(29) The high endo stereoselectivity observed in the reaction of trans-crotonaldehyde with acylaminobutadienes 9 and 19 is surprising in light of the low endo stereoselectivity reported for the reaction of this dienophile with cyclopentadiene, ${ }^{18}$ and the moderate endo stereoselectivity observed in the reaction of diene 9 and methyl acrylate. ${ }^{19}$ Whether the acylaminobutadienes or cyclopentadiene is unusual in this regard is the object of current attention in our laboratory.

(30) H. Booth, D. V. Griffiths, and M. L. Jozefowicz, J. Chem. Soc., Perkin Trans. 2, 751 (1976); F. W. Vierhapper and E. L. Eliel, J. Org. Chem., 42, 51 (1977).

(31) A full analysis of the ${ }^{13} \mathrm{C}$ NMR spectra of 2,5-substituted cis-decahydroquinolines will be reported elsewhere.

(32) Tetrahydrofuran (THF) was distilled from benzophenone and sodium immediately prior to use, and 4-tertbutylcatechol was purified by sublimation and recrystallization from hexane. All reactions were conducted under a nitrogen atmosphere. ${ }^{33}$ Concentrations were done using a rotary evaporator under reduced pressure. Commercial plates coated with $\mathrm{E}$. Merck silica gel were used for thin layer chromatography (TLC). W. R. Grace silica gel (grade 62) was used for column chromatography. ${ }^{1} \mathrm{H}$ and ${ }^{13} \mathrm{C}$ NMR spectra were determined with a Bruker WH-90 spectrophotometer at 90 and 22.6 $\mathrm{MHz}$, respectively. Chemical shifts are reported as $\delta$ values in parts per million relative to internal tetramethylsilane $=0 .{ }^{1} \mathrm{H}$ NMR coupling constants $(\Lambda)$ are reported in hertz and refer to apparant multiplicities, and not true coupling constants; abbreviations used are s, singlet; $d$, doublet; $t$, triplet; $\mathrm{m}$, complex multiplet. In a few cases these abbrevlations are also used to refer to the peak multiplicities observed in off-resonance decoupled ${ }^{13} \mathrm{C}$ NMR spectra. Infrared spectra were determined with a Beckman Acculab 2 spectrometer. Mass spectra were determined at $75 \mathrm{eV}$ with a Du Pont 21-492B double-focusing spectrometer at the Caltech analytical facility. High-performance liquid chromatography (HPLC) was performed with Waters components consisting of a 6000-A pump, U6K injector, and R401 differential refractometer. Gas chromatography (GLC) utilized a Varian Model 3700 chromatograph equipped with a differential thermal conductivity detector. Microanalyses were performed by Galbraith Laboratories, and agreed with calculated values within $\pm 0.4 \%$. Melting points were determined in capillary tubes with a Thomas-Hoover apparatus which was calibrated with known standards.

(33) W. S. Johnson and W. P. Schneider, "Organic Syntheses", Collect. Vol. IV, Wiley, New York, N.Y., 1963, p 132.

(34) A $30 \mathrm{~cm} \times 4 \mathrm{~mm} \mu$ Porasil column (ca. 3500 theoretical plates) and the eluent 9:1 hexane-ether were used for this analysis.

(35) A $12 \mathrm{ft} \times 3 / 8$ in. Porasil A column was used for this separation.

(36) (a) A $6 \mathrm{ft} \times 1 / 8$ in. $3 \% \mathrm{SP}-2401$ on $100 / 120$ Supelcoport glass column $100-140^{\circ} \mathrm{C}, \mathrm{N}_{2}$. (b) A $6 \mathrm{ft} \times 1 / 8$ in. $10 \%$ Carbowax $20 \mathrm{M}-2 \% \mathrm{KOH}$ on $80 / 100$ Chromosorb $W$ AW stainless steel column, $100-180^{\circ} \mathrm{C}, \mathrm{N}_{2}$.

(37) G. Defaye, Bull. Acad. Pol. Sci., Ser. Sci. Chim., 19, 1(1971); Chem. Abstr., $75,36457 \mathrm{~s}$ (1972).

(38) Spectroscopic data for this compound are reported in the microfilm edition of this article.

(39) NOTE ADDED IN PROOF. The use of 2.1 equiv. of the lithium salt of dimethyl methylphosphonate improves the yield of 24 to $78 \%$.

\title{
Bimolecular Reactions of Pyridinyl Radicals in Water and the Mechanism of $\mathrm{NAD}^{+}-\mathrm{NADH}$ Dehydrogenase Reactions ${ }^{\dagger}$
}

\author{
Edward M. Kosower, ${ }^{* 1 a, b}$ Avraham Teuerstein, ${ }^{\text {1a }}$ Hugh D. Burrows, ${ }^{1 c}$ \\ and A. J. Swallow*1d \\ Contribution from the Department of Chemistry, Tel-Aviv University, Ramat-Aviv, \\ Tel-Aviv, Israel, the Department of Chemistry, State University of New York, Stony Brook, \\ New York 11794, the Paterson Laboratories, Christie Hospital and \\ Holt Radium Institute, Manchester M20 9BX, England, and the Departamento de Quimica, \\ Universidade de Coimbra, Coimbra, Portugal. Received February 21, 1978
}

\begin{abstract}
Methyl-3-carbamido- (3.) and 4-carbamidopyridinyl (4.) radicals, generated through pulse radiolysis via le addition to the pyridinium ions, disappear by rather different pathways in water. 3. dimerizes in a $\mathrm{pH}$-independent reaction, whereas 4. reacts by electron transfer with protonated $4 \cdot\left(4 \mathrm{H}^{+} \cdot\right)$ and $4 \mathrm{H}^{+}$. reacts with other $4 \mathrm{H}^{+}$, leading to a pH-dependent reaction yielding pyridinium ion and a dihydropyridine. The latter reaction was defined with respect to both kinetics and products by a study of the disappearnce of 1-ethyl-and 1-tert-butyl-4-carbomethoxypyridinyl in aqueous solutions between $\mathrm{pH} 8$ and 9. At higher $\mathrm{pH}$, ester hydrolysis produces the highly reactive carboxylate-substituted radical. A $\log k-\mathrm{pH}$ plot suggests $\mathrm{p} K_{\mathrm{a}}$ differences between ester and amide radicals. Dimerization and electron-transfer reactions of 2, 3-, and 4. pyridinyl radicals generated by radiolytic techniques can be distinguished by careful measurement of $\mathrm{pH}$ changes of unbuffered solutions. Both the 3. dimer and the dihydropyridine from 4. react with water in $\mathrm{pH}$-dependent reactions to yield derivatives absorbing at much shorter wave lengths. The $\mathrm{p} K_{\mathrm{a}}$ for 3. is 1.4 , but the structurally similar radical from nicotinamide adenine dinucleotide (NAD.) is unprotonated at $\mathrm{pH} 0.3$. The NAD dimer reacts with water at about 0.03 of the rate found for 3. dimer. Some properties of the product of combination of the hydroxy-tert-butyl radical and 3. are compared to those of the 3. dimer. The suggested le, $\mathrm{H}^{+}$, pathway for $\mathrm{NAD}^{+}-\mathrm{NADH}$ enzyme-catalyzed reactions is made more attractive by our results.
\end{abstract}

\section{Introduction}

Two streams of thought underlie current interest in pyridinyl radicals (Py.). The first began with the work of Gomberg on the triphenylmethyl radical and proceeded through dissociable

$\uparrow$ The authors dedicate this paper to the memory of Gabriel Stein, late Professor at the Hebrew University, Jerusalem, who contributed so significantly to the field of the present paper and to other areas of radiation chemistry, through both his own work and his enthusiastic encouragement of others. pyridinyl radical dimers, ${ }^{2}$ dialkylbipyridylium dications and cation radicals ${ }^{3,4}$ (viologen, Paraquat ${ }^{5,6}$ ), and stable, isolable pyridinyl radicals. ${ }^{7}$ The second began with the discovery that two of the most important coenzymes in biological systems, NAD and NADP, ${ }^{8}$ had pyridiunium rings as their active centers, ${ }^{9}$ found stimulus in le reactions of dihydropyridines, ${ }^{10}$ receded somewhat amidst the controversy involving $1 \mathrm{e}$ vs. $2 \mathrm{e}$ reductions, ${ }^{11}$ regained strength through the pulse radiolytic 


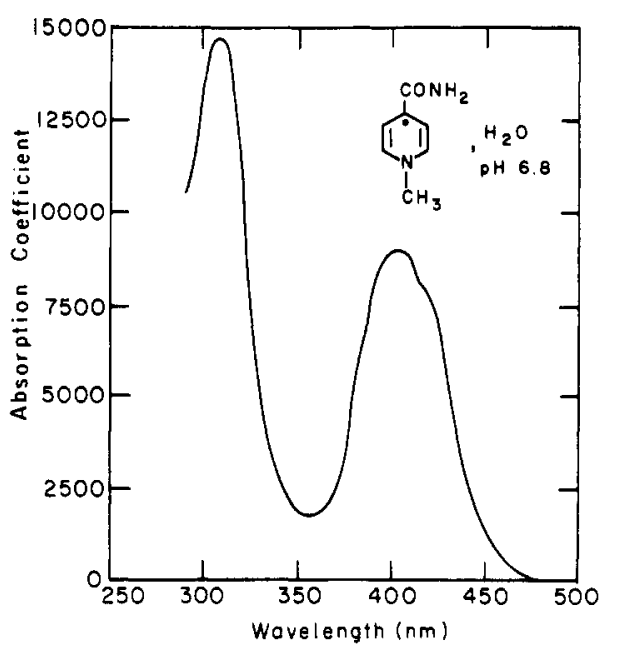

Figure 1. A spectrum of 1-methyl-4-carbamidopyridinyl radical (4-) generated through pulse radiolysis of a solution of the corresponding pyridinium ion in phosphate-formate buffer, $\mathrm{pH}$ 6.8. The low-intensity visible absorption is not shown here but is described eisewhere (E. M. Kosower, E. J. Land, and A. J. Swallow, J. Am. Chem. Soc., 94, 986 (1972).

generation of the NAD radical, ${ }^{13}$ and continues at present with suggestive evidence from many recent model experiments..$^{13-16}$ The mechanistic question of whether or not NAD-catalyzed reactions proceed via a single two-electron ("hydride-transfer") step (eq 1) or a pair of one-electron steps accompanied by proton transfer (eq 2 ) is still open and requires a detailed understanding of the behavior of pyridinyl radicals in aqueous systems.

$$
\begin{gathered}
\mathrm{Py}^{+}+\mathrm{RH} \rightarrow \mathrm{PyH}+\mathrm{R}^{+} \\
\mathrm{Py}^{+}+\mathrm{RH} \rightarrow \mathrm{Py} \cdot+\mathrm{RH}^{+} . \\
\mathrm{Py}+\mathrm{RH}^{+} . \rightarrow \mathrm{PyH}^{+} \cdot+\mathrm{R} \cdot \\
\mathrm{PyH}^{+} .+\mathrm{R} \cdot \rightarrow \mathrm{PyH}+\mathrm{R}^{+}
\end{gathered}
$$

To simplify the discussion of the small number of pyridinyl radicals with which we shall be concerned, we adopt the following abbreviations: 3., 4., 4EE., 4EB., NAD. ${ }^{17}$ and give some of the key formulas below.<smiles></smiles>

Py.<smiles>Cc1cccc(C=O)c1</smiles>

3.<smiles>Cc1ccc(C(N)=O)cc1</smiles>

4.<smiles></smiles>

经䤚.
The first simple pyridinyl radicals observed in water solutions were 3. and NAD., generated through pulse radiolysis of the corresponding pyridinium ions. Both disappeared at high rates in bimolecular reactions with products presumed to be dimers. ${ }^{12}$ Later, Kosower, Teuerstein, and Swallow ${ }^{18}$ discovered that the 4. radical could be generated in the same way and also disappeared in a bimolecular reaction. However, it was found that the reaction of the 4- was strongly influenced by $\mathrm{pH}$, whereas that of 3. was essentially unaffected. Neta and Patterson ${ }^{19}$ confirmed these findings for 4 - and made useful observations concerning the $\mathrm{p} K_{\mathrm{a}}$ of 3. and 4. radicals and about the mechanisms involved in the reaction of the radicals. Data reported by Brühlmann and Hayon ${ }^{20}$ for $3 \cdot$ and related radicals agree in many respects with the other results.

Many important points were left unclear or untouched by the previous work. In particular, the striking difference in the mechanism of reaction of 3. and 4. radicals should show up as a sharp difference in the nature of the products. Further, a clear dependence on $\left(\mathrm{H}^{+}\right)$, equivalent to defining the reaction, $4 .+$ $4 \mathrm{H}^{+}$., was not established. In the present work, we present information on these points and, in addition, kinetic results and evidence on the products and their behavior.

\section{Results}

Generation of Pyridinyl Radicals. The 1-methylcarbamidopyridinyl radicals, 3. and 4., and NAD. were produced through le reaction of the corresponding pyridinium compounds, utilizing le-transfer agents formed by pulse radiolysis of appropriate solutions. Reductions proceeded according to eq $3 a-c$. The chemical basis for favoring high concentrations of particular species in the solutions being pulsed is given elsewhere. ${ }^{22}$

$$
\begin{gathered}
\mathrm{Py}^{+}+\mathrm{e}^{-} \rightarrow \mathrm{Py} . \\
\mathrm{Py}^{+}+\mathrm{CO}_{2}^{-} \cdot \rightarrow \mathrm{Py} . \\
\mathrm{Py}^{+}+\left(\mathrm{CH}_{3}\right)_{2} \cdot \mathrm{COH} \rightarrow \mathrm{Py} .
\end{gathered}
$$

The pyridinyl radicals are readily recognized by their characteristic absorption spectra (three bands, two strong and one weak, past $270 \mathrm{~nm})^{7}$ and their high rates of formation $\left(k_{3 a}\right.$ $>10^{10} \mathrm{M}^{-1} \mathrm{~s}^{-1}$ ). Maxima are cited in the Experimental Section. The UV spectrum of 4., as generated by pulse radiolysis, is illustrated in Figure 1.

The 4-ester radicals (4EE. and 4EB.) are stable enough to be prepared by a chemical procedure, reduction with sodium amalgam in acetonitrile in the absence of oxygen, carried out on a vacuum line (eq 4).23,24 Absorption coefficients are es-

$$
\text { 1-R-4-COOCH}{ }_{3} \mathrm{Py}^{+} \underset{\mathrm{CH}_{3} \mathrm{CN}}{\stackrel{\mathrm{Na}(\mathrm{Hg})}{\longrightarrow}} 1-\mathrm{R}-4-\mathrm{COOCH}_{3} \mathrm{Py} \text {. }
$$

tablished by titration. The spectroscopic data for 4EB. in acetonitrile are given elsewhere. ${ }^{24}$ For comparison with the other pyridinyl radicals, maxima for $4 \mathrm{EE}$ - are cited in the Experimental Section.

$\mathrm{p} K_{\mathrm{a}}$ of Radicals. Acid produces a shift of the uncorrected absorption maxima of 3. from 280 and $420 \mathrm{~nm}$ to 300 and 440 $\mathrm{nm}$, attributed to protonation of the carbonyl oxygen atom. ${ }^{18-20 a, b}$ Analysis by a graphical procedure ${ }^{20 a}$ of the effect of $\mathrm{pH}$ on the absorption at $470 \mathrm{~nm}$ led to a $\mathrm{p} K_{\mathrm{a}}$ value of 1.43 $( \pm 0.07)$, in agreement with that found by others. ${ }^{19,20} \mathrm{The} \mathrm{p} K_{\mathrm{a}}$ of 4. was determined in the same way as $2.0 \pm 0.1$, in good agreement with the value of 2.1 reported for 1-hexyl-4-carbamidopyridinyl radical. ${ }^{19}$ The $405-n m$ maximum of 4 - shifts to $425 \mathrm{~nm}$ in the protonated form. The $\mathrm{p} K_{\mathrm{a}}$ of the 1-tertbutylcarbomethoxypyridinyl radical (4EB.) is estimated as ca. 0.6 from the $\log k$ vs. pH plot (Figure 2) (see below).

The $400-\mathrm{nm}$ peak of the NAD. radical found at $\mathrm{pH} 7$ is found in the same position in a $\mathrm{pH} 0.4$ solution, implying that the pyridinyl radical is not protonated. However, the short wavelength absorption (containing contributions from both the pyridinyl radical and adenine) is shifted $10 \mathrm{~nm}$ to longer wavelengths. Further, in ca. $1.5 \mathrm{M} \mathrm{HClO}_{4}$ the $400-\mathrm{nm}$ band shifts to $430( \pm 5) \mathrm{nm}$, giving a lower limit to the $\mathrm{p} K_{\mathrm{a}}$ of the NAD radical.

Kinetics of Radical Disappearance. As we reported in our preliminary communication, ${ }^{18}$ the most striking aspect of the behavior of the 3 . and 4 . radicals in water was that 3. disappeared in a virtually $\mathrm{pH}$-independent reaction while the reaction of 4 - with itself was strongly $\mathrm{pH}$ dependent. We then noted that 4EE. disappearance could be followed (with difficulty) at $\mathrm{pH} 8.0$. In order to define the $\mathrm{pH}$ dependence for the reaction of 4-substituted radicals further, the disappearance of the 4EB. radical was examined between $\mathrm{pH} 8.0$ and 11.0. A linear dependence of $\log k$ on $\left[\mathrm{H}^{+}\right]$was found between $\mathrm{pH}$ 8.0 and ca. 9.2, the rate decreasing in the expected fashion. At higher $\mathrm{pH}$ values, the rate increased, the rate being first order 
Table I. Kinetic Constants for the Disappearance of Pyridinyl Radicals in Water ${ }^{a}$

\begin{tabular}{|c|c|c|c|c|}
\hline radical & $\mathrm{pH}$, buffer ${ }^{b}$ & method $c$ & $\log k^{d}$ & ref \\
\hline 3. & $\begin{array}{l}0.46, \mathrm{H} \\
7.20, \mathrm{P}\end{array}$ & $\begin{array}{l}\mathrm{p} \\
\mathrm{p}\end{array}$ & $\begin{array}{l}9.06 \\
9.03\end{array}$ & $\begin{array}{l}e \\
e f\end{array}$ \\
\hline NAD. & $\begin{array}{ll}0.4, & \mathrm{H} \\
7.2, & \mathrm{P}\end{array}$ & $\begin{array}{l}p \\
p\end{array}$ & $\begin{array}{l}8.64 \\
8.11\end{array}$ & $\begin{array}{l}e \\
f\end{array}$ \\
\hline 4. & $\begin{array}{l}1.44, \mathrm{H} \\
1.89, \mathrm{H} \\
2.35, \mathrm{H} \\
2.84, \mathrm{H} \\
3.31, \mathrm{H} \\
3.43, \mathrm{~F} \\
4.07, \mathrm{~F} \\
5.62, \mathrm{P} \\
6.63, \mathrm{P}\end{array}$ & $\begin{array}{l}p \\
p \\
p \\
p \\
p \\
p \\
p \\
p \\
p\end{array}$ & $\begin{array}{l}8.66 \\
8.61 \\
8.61 \\
8.33 \\
8.01 \\
8.12 \\
7.72 \\
6.43 \\
5.26\end{array}$ & $\begin{array}{l}e \\
e \\
e \\
e \\
e \\
e \\
e \\
e \\
e\end{array}$ \\
\hline 4EE. & $8.00 \mathrm{P}$ & $v$ & 3.28 & $g$ \\
\hline 4EB. & $\begin{array}{r}8.00, \mathrm{P} \\
8.25, \mathrm{~B} \\
8.68, \mathrm{~B} \\
8.96, \mathrm{C} \\
9.67, \mathrm{C} \\
9.91, \mathrm{C} \\
10.34 \mathrm{C} \\
10.64 \mathrm{C} \\
10.85, \mathrm{C}\end{array}$ & $\begin{array}{l}v \\
v \\
v \\
v \\
v \\
v \\
v \\
v \\
v\end{array}$ & $\begin{array}{c}2.71 \\
2.27 \\
2.08 \\
1.76 \\
-2.79^{h} \\
-2.17^{h} \\
-1.91^{h} \\
-1.84^{h} \\
-1.52^{h}\end{array}$ & $\begin{array}{l}e \\
e \\
e \\
e \\
e \\
e \\
e \\
e \\
e\end{array}$ \\
\hline
\end{tabular}

${ }^{a}$ Defined by $-\mathrm{d}[\mathrm{Py} \cdot] / \mathrm{d} t=2 k[\mathrm{Py} \cdot]^{2} \cdot{ }^{b} \mathrm{H}=$ perchloric acid; $\mathrm{F}=$ sodium formate-formic acid; $\mathrm{A}=$ acetic acid-sodium acetate; $\mathrm{P}=$ phosphate; $\mathrm{FP}=$ sodium formate-phosphate; $\mathrm{B}=$ barbital; $\mathrm{C}=$ carbonate. ${ }^{c} \mathrm{p}=$ pulse radiolysis; $\mathrm{v}=$ vacuum-line technique. ${ }^{d} k$ in $\mathrm{dm}^{3} \mathrm{~mol}^{-1} \mathrm{~s}^{-1}$, epresent work, with $\epsilon_{400}=8900 \mathrm{M}^{-1} \mathrm{~cm}^{-1}$. $f$ The value given for the rate constant for the decay of 3 . in ref $12 \mathrm{a}$ and 18 was calculated incorrectly and is now superseded. The rate constant for the decay of NAD was correct. Comparisons of electrochemical and pulse-radiolysis data [C. O. Schmakel, K. S. V. Santhanam, and P. J. Elving, J. Am. Chem. Soc., 97, 5083 (1975)] now need to be revised. 8 Reference $18 .{ }^{h}$ Pseudo-first order reaction with $\mathrm{OH}^{-}$which supersedes the bimolecular reaction at the concentrations used for the $\mathrm{pH}$ values given. $k$ in $\mathrm{s}^{-1}$.

in the pyridinyl radical and $\log k$ linearly dependent upon the $\mathrm{pH}$. Moderately rapid hydrolyses of ester, $k_{2}=50 \mathrm{M}^{-1} \mathrm{~s}^{-1}$, accounted for the results (eq 5 ). The kinetic constants for py-

$$
\left(\mathrm{CH}_{3}\right)_{3} \stackrel{\mathrm{CN}}{=}-\mathrm{COOCH}_{3} \stackrel{\mathrm{OH}^{-}}{\longrightarrow}\left(\mathrm{CH}_{3}\right)_{3} \mathrm{CN}^{-}-\mathrm{COO}^{-}
$$

ridinyl radical reactions in aqueous systems are collected in Table I, and the $\mathrm{pH}$ dependence is illustrated by the plots in Figure 2.

Initial Products of Radical Reactions. The radical 3. at $\mathrm{pH}$ 7.2 gives rise to a product with $\lambda_{\max } 355( \pm 5) \mathrm{nm}$. This is very similar to the maximum obtained after $\gamma$ radiolysis of a solution of $3^{+}$with identical composition and like the absorption reported after $\mathrm{X}$ irradiation of oxygen-free aqueous solutions of $3^{+}$containing $0.5 \mathrm{M}$ ethanol. ${ }^{25}$ The instability of the product in acidic solutions will be described in the next section. The NAD- radical yielded a product with $\lambda_{\max } 355( \pm 5) \mathrm{nm}$ which is also unstable in acidic solution (see below).

Using tert-butyl alcohol in place of isopropyl alcohol or formate as hydroxyl radical scavenger, products were also formed from the reaction of 3- or NAD- with hydroxy-tertbutyl radical (HtB- formed in the scavenging reaction) at rates comparable to those of the 3. +3. or NAD + NAD- reactions. Although the absorption maxima were not very different from those of products formed in the presence of isopropyl alcohol or formate, a clear distinction could be made on the basis of fluorescence studies. Following radiolysis of solutions of $3^{+}$or

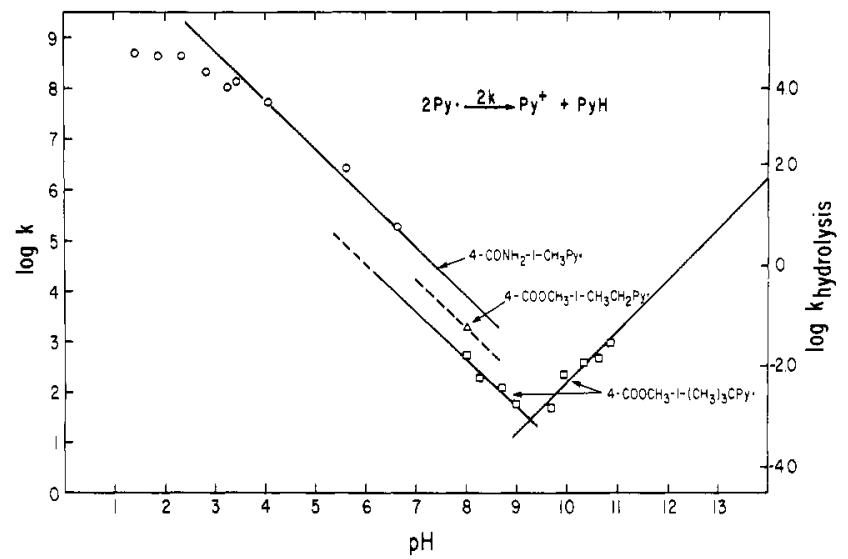

Figure 2. A plot of $\log k$ for the diappearance of a number of pyridinyl radicals in aqueous solution as a function of $\mathrm{pH}$. The slopes of the plots are not far from 1. (The dashed line shown for the 1-ethyl-4-carbomethoxypyridinyl radical, $4 \mathrm{EE}$, is given so as to suggest a $\mathrm{p} K_{\mathrm{a}}$ difference.) The $\mathrm{p} K_{\mathrm{a}}$ for the ester radical is obviously lower than for the amide radical; i.e., the pyridinyl ester is a stronger acid than the pyridinyl amide. Apparently, the 1-alkyl group has a substantial influence on the basicity of the pyridinyl radical, an effect also seen in the position of the visible absorption band [E. M. Kosower, H. P. Waits, A. Teuerstein, and L. C. Butler, J. Org. Chem., 43, 800 (1978)]. The units for the second-order disappearance of pyridinyl radicals are $\mathrm{dm}^{3} \mathrm{~mol}^{-1} \mathrm{~s}^{-1}$. The hydrolysis reaction of the ester controls the chemistry of the solution at $\mathrm{pH}$ values greater than about 9.25 . The units for the hydrolysis rate constants are $\mathrm{s}^{-1}$. The estimated second-order rate constant for the hydrolysis reaction is $50 \mathrm{dm}^{3} \mathrm{~mol}^{-1} \mathrm{~s}^{-1}$.

$\mathrm{NAD}^{+}$in the presence of tert-butyl alcohol, the products were found to possess broad, structureless fluorescences around 460 nm which were completely formed within less than $40 \mathrm{~ms}$. However, while the emission maxima were in the same region as the NADH fluorescence, the product from $\mathrm{NAD}^{+}$was found not to be NADH, when tested for coenzyme activity using lactic dehydrogenase. For $3^{+}$the fluorescence intensities of the products of pyridinyl radical $+\mathrm{HtB}$ - reaction were at least five times greater than those of the product(s) when isopropyl alcohol was used as scavenger, ${ }^{27}$ and when formate was used no significant fluorescence was detected.

The behavior of the products is accounted for by radical combination products, i.e., dimers from reactions of the same radicals and combination products for cases in which the reacting radicals are different (eq 6 and 7). Assignment of

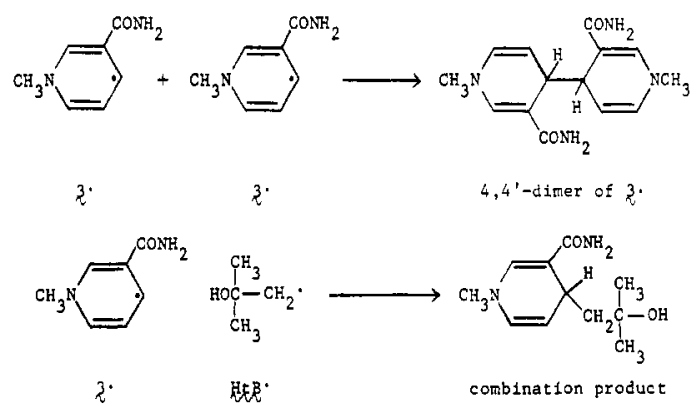

structure is made on the basis of: (a) mechanism of formation, since spin densities of radicals are highest at 4-;7,19,28-29a (b) known formation of 4,4'-dimers (e.g., Paraquat); (c) NMR results for related cases; $25 a$ (d) the stability of radicals substituted by alkyl groups at the 4 position.

The disappearance of 4- species does not lead to any products with absorption maxima at wavelengths longer than $300 \mathrm{~nm}$. At $\mathrm{pH}$ values lower than 9 , the ultraviolet absorption corresponds to a yield of $50 \%$ of the material in the form of the 4carbomethoxypyridinium ion, suggesting the disproportionation reaction (to $4 \mathrm{EE}$ - and $4 \mathrm{PMH}$ ) shown in eq $8 .{ }^{25} \mathrm{At}$ higher 
<smiles>CCN1C=CC(C(=O)OC)C=C1</smiles><smiles>CCN1C=CC(C(C)=[OH+])C=C1</smiles><smiles>CCCCC</smiles>

$4 \mathrm{EER}^{+}$

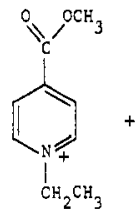

4EE ${ }^{+}$

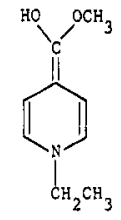

4PMH ("eno1")
(8)

$\mathrm{pH}$ values, a more complex ultraviolet absorption pattern could imply dimers or derivatives thereof (eq 9).<smiles>CC(C)(C)N1C=CC(C(=O)[O-])C=C1</smiles><smiles></smiles><smiles>CCCCC</smiles><smiles>COC(=O)C1(C(=O)OC)C=CC(C)(C)C=C1</smiles>

Instability of Initial Products of Radical Reaction. Almost all of the initial products formed in the reactions of radicals are unstable under some or all of the conditions used. The dimers and combination products disappear in acid-catalyzed hydration reactions to form monounsaturated amides, $\lambda_{\max }$ $290 \mathrm{~nm}^{26 \mathrm{a}}$ (eq 10.) Observed rates of hydration could be fol-

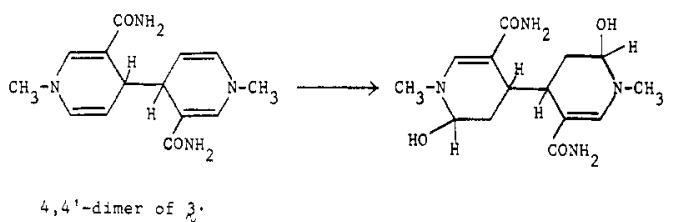

lowed at a number of $\mathrm{pH}$ values and are compatible with a process first order in hydrogen ion (Experimental Section). The NAD-dimer reacts with protons and water at about $1 \%$ of the rate for the 4,4'-dimer of 3., possibly due to a steric effect exerted by the group on nitrogen.

At $\mathrm{pH} 9$, the products of $4 \mathrm{EE}$. react further, the pyridinium ester hydrolyzing to the betaine, the 4PMH ("enol") hydrolyzing to yield products without absorption past $250 \mathrm{~nm}$. An attempt after reaction at $\mathrm{pH} 6$ to obtain the NMR spectrum of 4PMH failed because of the instability of the compound in aqueous solutions but did reveal the ethyl group, suggesting hydrolysis according to the scheme shown in eq 11 . If the ester

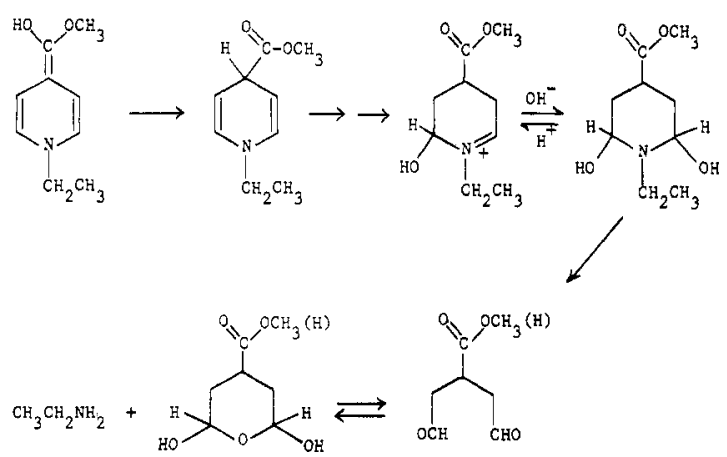

group shown in the dialdehyde hydrolyzed, the only hydrogens which would be unexchanged with the $\mathrm{D}_{2} \mathrm{O}$ used as solvent would be those originally in the 2,6 positions. Such hydrogens would be rather difficult to observe under our conditions. Since the NMR of the pyridinium salt (methyl group of ester, methyl group of ethyl, and ring hydrogens) were present in the spectrum and since the methyl groups of the salt had approximately the same integrated strength as the methyl groups assigned to the hydrolysis product, we think that the scheme shown in eq 11 is required to explain the "loss" of protons. Direct evidence for the formation of alkylamine was obtained from radiolysis experiments

pH Changes on Radiolysis. Irradiation of solutions of 1-
Table II. pH Changes upon Irradiation of Solutions of 1-Methyl 2-, 1-Methyl-3-, or 1-Methyl-4-carbamidopyridinium Ions in 0.5 M Isopropyl Alcohol-Water

\begin{tabular}{ccccccc}
\hline & \multicolumn{6}{c}{$\mathrm{pH}$ after irradiation } \\
\cline { 2 - 7 } compd & 0 & $5 \mathrm{~min}$ & $10 \mathrm{~min}$ & $15 \mathrm{~min}$ & $20 \mathrm{~min}$ & $60 \mathrm{~min}^{b}$ \\
\hline $\mathbf{4}^{+}$ & 7.00 & 7.84 & 8.24 & 8.47 & 8.49 & 8.40 \\
$\mathbf{3}^{+}$ & 6.81 & 4.16 & 4.17 & 3.95 & 3.54 & 3.24 \\
$\mathbf{2}^{+}$ & 6.71 & 5.12 & 4.72 & 4.55 & 4.46 & 4.33 \\
\hline
\end{tabular}

${ }^{a}$ Fricke dosimetry indicated an approximate $7000 \mathrm{rad} / \mathrm{min}$, but our experimental solutions were not prepared under absolutely controlled conditions and the expected $G$ value was approached only after considerable irradiation. The trends, however, are clearly in agreement with eq $13-15 .{ }^{b}$ Large-scale irradiation for product examination.

methyl-3-carbamido- and 1-methyl-4-carbamidopyridinium perchlorates in water containing $0.5 \mathrm{M}$ isopropyl alcohol but no buffer led to $\mathrm{pH}$ changes. Data for 1-methyl-2-carbamidopyridinium perchlorate solutions irradiated under the same conditions were also obtained, the radical 2 . being the expected<smiles>Cc1ccccc1N</smiles>

intermediate as shown by pulse radiolysis experiments ${ }^{26 \mathrm{~b}} \mathrm{Ir}$ radiation with ${ }^{60} \mathrm{Co} \gamma$ rays of the solution of $3^{+}$led to the greatest decrease in $\mathrm{pH}$, with $\mathbf{2}^{+}$exhibiting substantially less $\mathrm{pH}$ change. The $\mathrm{pH}$ of the irradiated $\mathbf{4}^{+}$solution actually increased in $\mathrm{pH}$ by a small amount, a result which was traced to the formation of a small amount of methylamine, enough to convert the net change in $\mathrm{pH}$ into a small increase. Given the quantities of substances used and the radiation doses applied, the results for the three compounds may be summarized to a reasonable approximation by the following equations. The data are given in Table II, and the details of the ${ }^{60} \mathrm{Co}$ irradiations are noted in the Experimental Section.

$$
\text { (proton formation) })^{22}
$$

$3 \mathrm{H}_{2} \mathrm{O} \stackrel{\gamma \text { rays }}{\longrightarrow} 3 \cdot \mathrm{OH}+3 \mathrm{H}^{+}+3 \mathrm{e}^{-}$

$3 \mathrm{e}^{-}+3 \mathrm{Py}^{+} \rightarrow 3 \mathbf{P y}$.

$3 \cdot \mathrm{OH}+3 i-\mathrm{PrOH} \rightarrow 3 \mathrm{H}_{2} \mathrm{O}+3\left(\mathrm{CH}_{3}\right)_{2} \mathrm{COH}$

$3\left(\mathrm{CH}_{3}\right)_{2} \cdot \mathrm{COH}+3 \mathrm{Py}^{+} \rightarrow 3 \mathrm{Py} \cdot+3 \mathrm{H}^{+}+3\left(\mathrm{CH}_{3}\right)_{2} \mathrm{CO}$

$3 \mathrm{H}_{2} \mathrm{O}+6 \mathrm{Py}^{+}+3 i-\mathrm{PrOH} \rightarrow 6 \mathrm{Py} \cdot+6 \mathrm{H}^{+}+3\left(\mathrm{CH}_{3}\right)_{2} \mathrm{CO}$

3. + 3. $\rightarrow$ 3-3 dimer (no $\mathrm{H}^{+}$consumption)

2. $+2 \cdot+\mathrm{H}^{+} \rightarrow 2^{+}+2 \mathrm{H}$ (1 proton consumed/Py. formed; i.e. one-half of protons formed)

4. $+4 \cdot+\mathrm{H}^{+} \rightarrow 4^{+}+4 \mathrm{H}$

$4 \mathrm{H}+\mathrm{H}^{+} \rightarrow \mathrm{CH}_{3} \mathrm{NH}_{2}$ (2 protons consumed $/ \mathbf{P y} \cdot$ formed; i.e., all protons formed; some additional protons consumed by methylamine; cf. eq 11)

$\mathrm{CH}_{3} \mathrm{NH}_{2}+\mathrm{H}_{2} \mathrm{O} \rightarrow \mathrm{CH}_{3} \mathrm{NH}_{3}{ }^{+}+\mathrm{OH}^{-}$

A second type of radiolysis experiment was carried out on $3^{+}$and $4^{+}$solutions containing $0.5 \mathrm{M}$ isopropyl alcohol and $10^{-4} \mathrm{M}$ sodium hydroxide. An ac conductivity bridge was used to detect conductance changes produced by: $0.5 \mathrm{krad}$ pulses of electrons. An immediate change in conductivity corresponding to eq 12 was seen, with no subsequent further changes over a period of at least several seconds. The 3 - radicals react with one another with a rate constant, $k$, of $10^{9} \mathrm{M}^{-1} \mathrm{~s}^{-1}$, independent of $\mathrm{pH}$. Their disappearance is not, therefore, accompanied by any consumption of protons and must proceed as in eq 13 . The 
4. radicals react with one another so slowly under these conditions that no reaction should be observed.

\section{Discussion}

The most significant part of our current work is the sharp difference we have established between the reactions of 3. and 4. radicals. The 3. radicals react with one another to yield dimer, and the 4. radicals react with one another (primarily via a process which involves protonation of one 4 - radical) to yield disproportionation products, formed by electron transfer between the reactant species. We can summarize these results in the form of two general equations, eq 16 and 17 .

$$
\begin{gathered}
3 \mathrm{Py} \cdot+3 \mathrm{Py} \cdot \rightarrow 3 \mathrm{Py}-3 \mathrm{Py} \text { (probably } 4,4^{\prime} \text { ) } \\
4 \mathrm{Py} \cdot+4 \mathrm{PyH} \cdot+\rightarrow 4 \mathrm{Py}^{+}+4 \mathrm{PyH}
\end{gathered}
$$

In considering the reasons for this divergence of behavior, it became clear from the work of Mumm and Ludwig ${ }^{2}$ that steric hindrance at the 4 position promoted the formation of 3. radicals from their dimers. The importance of the 4 position is evident in the spin distributions for many pyridinyl radicals $7,28,29 a, b$ and supported by the calculations of Neta and Patterson. ${ }^{19}$ If we were able to hinder the dimerization reaction, a 3- radical might then participate in le reactions. An enzyme which binds NAD - might be regarded as a highly bulky, sterically hindering substituent on the pyridinium (or pyridinyl) ring. In fact, Gunsalus and co-workers ${ }^{30}$ have produced NADP. radicals in the presence of ferredoxin-NADP reductase and detected NADPH as the final product. Without the enzyme, dimer resulted. It is not clear whether or not the NADP- is a substrate for the enzyme or simply functions as a 1 -electron reducing agent, reverting to $\mathrm{NADP}^{+}$which becomes converted to NADPH by reduced enzyme. Nevertheless, we could predict that a suitably substituted 3. radical might undergo disproportionation in an electron-transfer reaction, a result we could easily detect by a $\mathrm{pH}$ change after radiolysis or by a study of the kinetics of radical disappearance as a function of $\mathrm{pH}$.

Viewed in this light, our results provide a suitable background for continued consideration of the le pathway for NAD-catalyzed enzymatic reactions. Bruice ${ }^{31}$ has given arguments in favor of the closely related le $+\mathrm{H} \cdot$ pathway for such enzymatic reactions. The early proposal for such a pathway by Kosower ${ }^{32}$ has been discussed elsewhere ${ }^{7}$ and has been summarized in short form in eq $2 a-c$.

We might note that the quenching of the typical 1,4-dihydronicotinamide fluorescence observed in the $4,4^{\prime}$-dimers is no doubt due to charge transfer ${ }^{33}$ from the unexcited ring to the excited ring (or vice versa) with the electron transfer taking place via overlap of the amide substituent with the $\pi$ system of the second ring. This would explain the photochemical results found by Berson and Brown ${ }^{34}$ who found that a nitro group capable of overlap with the dihydropyridine ring could be reduced photochemically but one which did not engage in overlap was left unaffected by irradiation.

\section{Experimental Section}

Materials. 1-Methyl-2-carbamidopyridinium perchlorate, $\mathrm{mp}$ $114-116^{\circ} \mathrm{C}$; 1-methyl-3-carbamidopyridinium perchlorate, $\mathrm{mp} 146$ ${ }^{\circ} \mathrm{C} ;{ }^{35}$ and l-methyl-4-carbamidopyridinium perchlorate, mp 185-186 ${ }^{\circ} \mathrm{C}^{35}$ were prepared from the corresponding iodides by treatment with $\mathrm{AgClO}_{4}$ in methanol, followed by crystallization from methanol. The 1 -methyl- $x$-carbamidopyridinium iodides precipitated upon treatment of the 1-methyl- $x$-carbomethoxypyridinium iodides with methanol saturated with ammonia. ${ }^{36} \mathrm{NAD}^{+}, \mathrm{NADH}$, and lactic dehydrogenase were obtained from Boehringer.

Isopropyl alcohol (Fluka, puriss) was boiled briefly and cooled during bubbling with pure $\mathrm{N}_{2}$. Water, radiolysis: Deionized water was brought to $\mathrm{pH} 8$ with $0.1 \mathrm{M} \mathrm{NaOH}$, distilled from $\mathrm{KMnO}_{4}$, and redistilled. The purified water was freed of $\mathrm{CO}_{2}$ by boiling and allowing to cool during prolonged bubbling with pure $\mathrm{N}_{2}(2 \mathrm{~h})$ ( $\left.\mathrm{pH} 6.9-7.0\right)$. Pulse radiolysis: Double-distilled water was used.

1-Alkyl-4-carbomethoxypyridinyls were prepared by reduction of the corresponding pyridinium iodides ${ }^{24}$ using sodium amalgam in acetonitrile under oxygen-free conditions in an all-glass apparatus. (Vacuum line techniques are required.) $\lambda_{\max }(\mathrm{nm})\left(\epsilon_{\max }\right)\left(\mathrm{CH}_{3} \mathrm{CN}\right)$ : 4EE. 304 (11 300), 395 (4700), 6326 (83)

Pulse Radiolysis Technique. Pulses of electrons (approximately $0.1-1.0 \mu \mathrm{s}, 10 \mathrm{MeV}$ ) were delivered from a linear accelerator. ${ }^{21} \mathrm{Op}-$ tical absorption of irradiated solutions was monitored at all necessary wavelengths and recorded as a function of time using Polaroid film. Data treatment was carried out as in earlier work, thiocyanate being used for dosimetry. ${ }^{37}$

Irradiations were carried out an argon-bubbled solutions containing either $0.1 \mathrm{M}$ sodium formate-formic acid, or isopropyl alcohol-0.1 $\mathrm{M}$ sodium phosphate. $\mathrm{pH}$ was controlled by the addition of perchloric acid or, in certain cases, sulfuric acid.

Spectroscopic Data. $\lambda_{\max }(\mathrm{nm})\left(\epsilon_{\max }\right): 2 \cdot 307$ (6500), 365 (3000), 900 (-); 3. 280 (10 200), 410 (4300), $1250(-)$; 4. 305 (15 700), 402 (8900), $650(\sim 80)$

Radiolysis Technique. Aqueous solutions of 1-alkyl- $x$-carbamidopyridinium perchlorates $\left(5 \times 10^{-3} \mathrm{M}\right)$ containing $0.5 \mathrm{M}$ isopropyl alcohol were made up within a glove bag under $\mathrm{N}_{2}$ using $\mathrm{CO}_{2}$-free solvents and then bubbled with pure $\mathrm{N}_{2}$ within the glove bag for 30 min. All pH measurements were made within the glove bag using an Orion digital $\mathrm{pH}$ meter.

Irradiations were made with the ${ }^{60} \mathrm{Co}$ source at the Weizmann Institute, Rehovot. Radiation doses were measured with a Fricke dosimeter. However, the technique used for preparing the solutions does not rigorously exclude oxygen or other electron-consuming impurities, requiring doses greater than those which could accurately be measured with the dosimeter. It was possible to obtain an approximate idea of the effective dose by carrying out a large-scale irradiation and measuring the amount of pyridinium salt (absorption) remaining after 60 min of irradiation: 1-methyl-2-carbamido (80\%), 1-methyl-3-carbamido (59\%), and 1-methyl-4-carbamido (74\%). Since disproportionation for the 2- and 4-radicals yields the starting pyridinium ion, these results imply amounts reacted of 40,41 , and $52 \%$, respectively, for the 2-, 3-, and 4-ions. At the concentrations used $\left(5 \times 10^{-3} \mathrm{M}\right), 2 \times 10^{-3} \mathrm{M}$ salt reacted. The dosimeter results $(7000$ $\mathrm{rad} / \mathrm{min}$ ) suggested that $2.5 \times 10^{-3} \mathrm{M}$ salt should have reacted [G $=6(\mathrm{cf}$. eq 10)]. The agreement is satisfactory and compatible with the limitations of the techniques used. The $\mathrm{pH}$ of the 3-solution indicated $6 \times 10^{-3} \mathrm{M} \mathrm{H}^{+}$or only $30 \%$ of that expected. Either the $3-4-\mathrm{h}$ delay between irradiation and measurement led to consumption of protons (i.e., slow hydrolysis of product) or else protons were consumed in another reaction such as half protonation of the dimer, which would lead to an ultraviolet spectrum similar to that of the unprotonated but diminished in intensity. In fact, the product has an estimated absorption coefficient at $295 \mathrm{~nm}$ of 10000 in place of the 40000 which might have been expected from the results of Kim and Chaykin. ${ }^{38}$ To simplify the discussion, the possible contribution of other dimers (e.g., $6,6^{\prime}$ or $4,6^{\prime}$, etc.) has been ignored. $25 \mathrm{~b}$

Methylamine formation was observed in the case of $4^{+}$(ca. $4.5 \times$ $10^{-6} \mathrm{M}$ ) and $2^{+}$(ca. $1 \times 10^{-6} \mathrm{M}$ ), using fluorescamine to generate a fluorescent product from methylamine and quantitative fluorimetry with a Perkin-Elmer MPF-4 spectrofluorimeter and comparison with known concentrations of methylamine-fluorescamine product. ${ }^{39}$ Thin-layer chromatography confirmed that the fluorescent product was indeed that derived from methylamine, readily distinguishable from the fluorescent product derived from $n$-butylamine. The formation of methylamine in radiolysis confirms the conclusions reached on the basis of the NMR spectrum of the product of reaction of 4EE. with itself in water at neutral $\mathrm{pH}$ (see following experiment).

Disproportionation of 1-Ethyl-4-carbomethoxypyridinyl Radical in Water. Tetramethylammonium phosphate, $\mathrm{pH} 5.94$, in $\mathrm{D}_{2} \mathrm{O}\left(2 \mathrm{~cm}^{3}\right)$ was mixed with ca. $50 \mathrm{mg}$ of 1-ethyl-4-carbomethoxypyridinyl $\left(\mathrm{CH}_{3} \mathrm{CN}\right.$ soln: solvent evapd, $\mathrm{CD}_{3} \mathrm{CN}$ introduced, solvent evapd, 0.4 $\mathrm{cm}^{3} \mathrm{CD}_{3} \mathrm{CN}$ introduced) with stirring. Within a short time, the blue-green color of the solution had changed to pale orange. A portion $\left(0.5 \mathrm{~cm}^{3}\right)$ of the mixture was poured into an NMR tube, the tube was sealed off, and the NMR spectrum was immediately taken. The 1. ethyl-4-carbomethoxypyridinium ion was readily identified: $\delta 9.11$, 8.41 (each doublet, ring $\mathrm{H}), 4.00\left(\mathrm{CH}_{3}\right.$ of ester), $1.63\left(\mathrm{CH}_{3}\right.$ of 1 ethyl). Quantitative analysis was not possible. The only other readily visible peaks were at $\delta 1.24$ and 0.90 . Each was a triplet. The ap- 
proximate ratio between the $\delta 1.63$ and the sum of the $\delta 1.24$ and 0.90 peaks was $1: 1$. No dihydropyridine ring protons could be seen, $\delta 4.5$ and 6.00 (see previous product study above). The dihydropyridine which must have formed as a result of disproportionation must have hydrolyzed, completely or partially after hydration, yielding ethylamine or a cyclic saturated amine in roughly equivalent amounts. The UV spectrum of the solutions after kinetic experiments shows that no UV-absorbing product except for the 1-ethyl-4-carbomethoxypyridinium ion is present (down to $200 \mathrm{~nm}$ ).

Disappearance of AEE. or 4EB in Water. An amount of radical sufficient to give a suitable optical density for kinetic studies (between ca. 0.01 and 1.0 ) was introduced into an all-glass apparatus in an acetonitrile solution. Most of the acetonitrile was removed, and a degassed buffer of the desired $\mathrm{pH}$ was added. The nominal $\mathrm{pH}$ of the buffer was that obtained before degassing (phosphate, $\mathrm{pH}$ 6-8; carbonate, $\mathrm{pH} 10-11$; barbital, $\mathrm{pH} \mathrm{8-9;} \mathrm{acetate,} \mathrm{pH} 5-5.5$ ), but the $\mathrm{pH}$ was taken as that measured after the completion of the kinetic run, since small amounts of acetonitrile change the $\mathrm{pH}$ of an aqueous buffer. Although a number of successful experiments were carried through in which the buffer was introduced directly from the breakseal onto the radical sample located within the cell with the Cary spectrophotometer running, it was usually simpler to mix outside the spectrophotometer and then quickly insert the cell in to the cell holder.

Plots of 1 /optical density -1 /optical density ${ }_{\text {inf }}$ against time gave linear plots for experiments carried out below $\mathrm{pH} 9.5$. At $\mathrm{pH} 9.7$ or above, the $\log$ of OD vs. time was linear, indicating a pseudo-firstorder reaction, since the constant varied with $\mathrm{pH}$.

The slope of the second-order plot times the extinction coefficient of the radical gave the bimolecular rate constants recorded in Table I. A UV spectrum taken after the completion of the kinetic runs below $\mathrm{pH} 9$ revealed a spectrum corresponding to that of the 1-alkyl-4carbomethoxypyridinium ion, $\lambda_{\max } 275 \mathrm{~nm}\left(\epsilon_{\max } 4400\right)$ in almost exactly $50 \%$ yield. The spectrum changed at a moderate rate to that of the 1-alkyl-4-carboxypyridinium ion, in exactly the way observed for an authentic solution of the 1-alkyl-4-carbomethoxypyridinium ion.

Hydration of Dimers of 3. and NAD. The loss of absorption at 355 (3. dimer) or at $350 \mathrm{~nm}$ (NAD-dimer) could be followed after pulse radiolysis of argon-saturated solutions of the appropriate salts containing $0.5 \mathrm{M}$ isopropyl alcohol and various amounts of perchloric acid. Slopes vs. $\mathrm{pH}$ were approximately -0.8 , indicating a process first order in $\mathrm{H}^{+}$. The rate constants, defined as rate $=k_{2}($ dimer $)\left(\mathrm{H}^{+}\right)$, were $102 \mathrm{M}^{-1} \mathrm{~s}^{-1}$ (3. dimer) and $0.9 \mathrm{M}^{-1} \mathrm{~s}^{-1}$ (NAD. dimer). A study of the temperature effect upon the hydration of the 3. at pH 1.44 led to an $E_{\mathrm{a}}$ of $48.1 \mathrm{~kJ} \mathrm{~mol}^{-1}$. Rate constants and activation energy are approximately $\pm 20 \%$. The hydration of 1,4-dihydro-3-carbamidopyridines is moderately sensitive to the nature of the $\mathrm{N}$ substituent, since $k_{2}$ for the 1 -benzyl derivative is ca. $5 \mathrm{M}^{-1} \mathrm{~s}^{-1}$, but the $k_{2}$ for the 1-(2,6-dichlorobenzyl) derivative is ca. $0.3 \mathrm{M}^{-1} \mathrm{~s}^{-1} .38$

Acknowledgment. The Israel Academy of Science is thanked for a grant to E.M.K. This work was supported in part by grants from the Cancer Research Campaign and the Medical Research Council (A.J.S.). H.D.B. is grateful to the Instituto de Alta Cultura for financial support. The authors appreciate the contribution of Professor J. H. Baxendale to the success of the pulse radiolysis conductivity experiment and the use of his ac conductivity bridge. Thanks are due to Dr. E. J. Land for his help in some of the experiments.

\section{References and Notes}

(1) (a) Tel-Aviv University. (b) SUNY, Stony Brook, (c) Coimbra; present address: Department of Chemistry, University of lfe, lle-lfe, Nigeria. (d) Paterson Laboratories, Manchester.

(2) (a) O. Mumm and H. Ludwig, Ber. Dtsch. Chem. Ges., 59, 1605 (1926). (b) A. T. Nielsen, D. W. Moore, J. H. Mazur, and K. H. Berry, J. Org. Chem., 29, 2898 (1964); cf. B. Schroeder, W. P. Neumann, J. Hollaender, and H. P. Becker, Angew. Chem., Int. Ed. Engl., 11, 850 (1972).

(3) E. M. Kosower and J. L. Cotter, J. Am. Chem. Soc., 86, 5524 (1964).

(4) A. J. Bara, A. Ledwith, and H. J. Shine, Adv. Phys. Org. Chem., 13, 156 (1976).

(5) L. Michaelis, Biochem. Z., 250, 564 (1932)

(6) Paraquat is the trade name for $1,1^{\prime}$-dimethyl-4,4'-bipyridylium dication (also known as methylviologen), a widely used herbicide. Chloroplasts reduce the dication to the cation radical which reacts with oxygen to form super- oxide ion, $\mathrm{O}_{2}^{-}$- and $\mathrm{H}_{2} \mathrm{O}_{2}$. These chemically reactive species apparently attack components of the membrane and eventually cause destruction of the plant. The kinetics and mechanism of the radical cation reaction with oxygen is thus a subject of considerable economic as well as scientific importance. Compare J. A. Farrington, M. Ebert, E. J. Land, and K. Fletcher, Biochim. Biophys Acta, 314, 372 (1973); and A. G. Evans, N. K. Dodson, and N. H. Rees, J. Chem. Soc., Perkin Trans. 2, 859 (1976). The direct importance of superoxide ion has been questioned by B. Goldberg and A. Stern, Mol. Pharmacol, 13, 832 (1977). Compare D. T. Sawyer, M. J. Gibian, M. M. Morrison, and E. T. Seo, J. Am. Chem. Soc., 100,627 (1978). See also J. A. Farrington, M. Ebert, and E. J. Land, J. Chem. Soc. Faraday Trans 1, 665 (1978).

(7) E. M. Kosower, in "Free Radicals in Biology", Vol. II, W. A. Pryor, Ed., Academic Press, New York, N.Y., 1976, Chapter 1.

(8) H. R. Mahler and E. H. Cordes, "Biological Chemistry", 2nd ed, Harper \& Row, New York, N.Y., 1971, pp 409-416.

(9) H. F. Fisher, E. E. Conn, B. Vennesland, and F. H. Westheimer, J. Biol. Chem., 202, 687 (1953).

(10) K. A. Schellenberg and L. Hellerman, J. Biol. Chem., 231, 547 (1958).

(11) B. Vennesland and F. H. Westheimer, in "The Mechanism of Enzyme ACtion", W. D. McElroy and B. Glass, Ed., Johns Hopkins Press, Baltimore Md., 1954, p 357

(12) (a) E. J. Land and A. J. Swallow, Biochim. Biophys, Acta, 162, 327 (1968). (b) 1-Ethyl-4-cyanopyridinyl radical was detected by cyclic voltammetry in buffered aqueous solution by W. M. Schwarz, E. M. Kosower, and I. M. Shain, J Am. Chem. Soc., 83, 3164 (1961). The first preparation of a pure pyridinyl radical, 1-ethyl-4-carbomethoxypyridinyl (4EE-) was communicated by E. M. Kosower and E. J. Poziomek J. Am. Chem. Soc., 85, 2035 (1963).

(13) J. J. Steffens and D. M. Chipman, J. Am. Chem. Soc., 93, 6694 (1971).

(14) A. Ohno and N. Kito, Chem. Lett., 369 (1972).

(15) D. J. Creighton, J. Hadju, G. Mooser, and D. S. Sigman, J. Am. Chem. Soc., 95, 6855 (1973).

(16) J. Hadju and D. S. Sigman, J. Am. Chem. Soc., 98, 6060 (1976).

(17) $3 .=1$-methyl-3-carbamidopyridinyl; 4. = 1-methyl-4-carbamidopyridinyl; 4EE. = 1-ethyl-4-carbomethoxypyridinyl; 4EB. = 1-tert-butyl-4-carbomethoxypyridinyl; NAD. = pyridinyl radical derived by 10 reduction of nicotinamide adenine dinucleotide. It should be pointed out that meta- $(m)$ and para $(p)$ are not correct as designators of substituent locations on the pyridine ring.

(18) E. M. Kosower, A. Teuerstein, and A. J. Swallow, J. Am. Chem. Soc., 95, 6127 (1973).

(19) P. Neta and L. K. Patterson, J. Phys. Chem., 78, 2211 (1974)

(20) (a) U. Brühlmann and E. Hayon, J. Am. Chem. Soc, 96, 6169 (1974). (b) That protonation occurs at the amide group rather than on the ring can be clearly seen by comparison of this spectrum with the spectrum of the product of hydrogen atom addition to the ring of the $N$-methylnicotinamide ion. The adduct spectrum shows a fairly sharp maximum at $340( \pm 5) \mathrm{nm}$; H. D. Burrows, A. J. Swallow, and E. M. Kosower, unpublished observations. (c) A. Albert and E. P. Serjeant, "The Determination of lonization Constants of Acids and Bases', 2nd ed, Chapman and Hall, London, 1973, p 52.

(21) J. P. Keene, J. Sci. Instrum., 41, 493 (1964); Quad. Arca Ric. EmiliaRomagna 1, 49, 63 (1972).

(22) A. J. Swallow, "Radiation Chemistry", Longman, London, 1973, pp 136-166.

(23) E. M. Kosower and H. P. Waits, Org. Prep. Proced. Int., 3, 261 (1971).

(24) Details for the 4EB. preparation are given elsewhere. E. M. Kosower, H P. Waits, A. Teuerstein, and L. C. Butler, J. Org. Chem., 43, 800 (1978)

(25) (a) G. Stein and A. J. Swallow, J. Chem. Soc., 396 (1958). (b) J. F. Biellmann, CNRS Strasbourg, private communication; cf. K. Kano and T. Matsuo, Bull. Chem. Soc. Jpn., 49, 3269 (1976), and F. T. McNamara, J. W. Nieft, J. F. Ambrose, and E. S. Huyser, J. Org. Chem., 42, 988 (1977). (c) The somewhat related compound 4-(methoxytrimethylsilylmethylene)- $N$-trimethy|silyl-1,4-dihydropyridine has been reported as a yellow oil, without detailed spectroscopic information. S. V. Ponomarev, H. P. Becker, W. P. Neumann, and $B$. Schroeder, Justus Liebigs Ann. Chem., 1895 (1975)

(26) (a) cf. A. C. Anderson, Jr., and G. Berkelhammer, J. Am. Chem. Soc., 80, 992 (1958); R. Segal and G. Stein, J. Chem. Soc., 5254 (1960).

(27) In the scavenging of hydroxyl radicals by isopropyl alcohol, $13.3 \%$ of the reaction proceeds via formation of $\mathrm{CH}_{2} \mathrm{CH}\left(\mathrm{CH}_{3}\right) \mathrm{OH}$ [K. D. Asmus, $\mathrm{H}$. Möckel, and A. Henglein, J. Phys. Chem., 77, 1218 (1973)]. The small percentage of fluorescent product formed here may result from crossreaction of these radicals with 3 .

(28) H. Zeldes and R. Livingston, J. Phys. Chem., 76, 3348 (1972); 77, 2076 (1973).

(29) (a) H. Zeldes, R. Livingston, and J. S. Bernstein, J. Magn. Reson., 21, 9 (1976). (b) J. K. Dohrmann and R. Becker, J. Magn. Reson., 27, 371 (1977).

(30) S. S. Chan, T. M. Nordlund, H. Frauenfelder, J. E. Harrison, and I. C. Gunsalus, J. Biol. Chem, 250,716 (1975).

(31) T. C. Bruice, Annu. Rev. Biochem, 45, 331 (1976)

(32) E. M. Kosower, Prog. Phys. Org. Chem., 3, 81 (1965).

(33) E. M. Kosower, H. Dodiuk, K. Tanizawa, M. Ottolenghi, and N. Orbach, J. Am. Chem. Soc., 97, $2167(1975)$

(34) J. A. Berson and E. Brown, J. Am. Chem. Soc., 77, 444(1975)

(35) E. M. Kosower and S. W. Bauer, J. Am. Chem. Soc., 82, 2191 (1960).

(36) J. Hermolin, unpublished results.

(37) G. E. Adams, J. W. Boag, J. Currant, and B. D. Michael, in "Pulse Radiolysis", M. Ebert, J. P. Keene, A. J. Swallow, and J. H. Baxendale, Ed., Academic Press, London, 1965, p 117.

(38) C. S. Y. Kim and S. Chaykin, Biochemistry, 7, 2339 (1968)

(39) S. de Bernardo, M. Weigele, V. Toome, K. Manhart, and W. Leimgruber, Arch. Biochem. Biophys., 163, 390 (1974). 